\title{
PLENITUD EXISTENCIAL Y EPICUREÍSMO EN LA POESÍA ÚLTIMA DE AURORA LUQUE ${ }^{1}$
}

\section{EXISTENTIAL PLENITUDE AND EPICUREANISM IN AURORA LUQUE'S LATEST WORK}

\author{
Josefa ÁLVAREZ VALADÉS \\ Le Moyne College (Estados Unidos) \\ alvarej@lemoyne.edu
}

\begin{abstract}
Resumen: El presente artículo se propone rastrear aspectos característicos de la doctrina epicúrea en los dos últimos poemarios publicados hasta la fecha por la poeta andaluza Aurora Luque: Cuaderno de Flandes y Personal y politico, ambos del año 2015. Tratamos en particular de analizar sus vínculos con un epicúreismo de corte más hedonista, que desarrollaran en su momento grandes poetas latinos como Horacio y Catulo. A través de este la poesía de Luque se vincula a una plenitud vital donde el cuerpo adquiere un papel protagonista que no está reñido con el disfrute a través de la cultura, la memoria o con la conciencia socio-política.
\end{abstract}

Palabras clave: Aurora Luque; Epicureísmo; carpe diem; cuerpo; memoria; conciencia políticosocial.

Abstract: The present article traces characteristic aspects of the epicurean doctrine in the latest two poetry collections published by the Andalusian poet Aurora Luque: Cuaderno de Flandes and Personal y político, both of 2015 . We try in particular to analyze their link with a more hedonistic Epicureanism, similar to the one that great Latin poets such as Horacio and Catulo once developed. Through this approach, Luque's poetry is linked to a vital fullness where the body takes a leading role that is not at odds with enjoyment through culture, memory or socio-political consciousness.

Keywords: Aurora Luque; Epicureanism; carpe diem; body; memory; political-social awareness.

\footnotetext{
${ }^{1}$ Este artículo se ha escrito en el marco del Proyecto de Investigación Felicidad y Literatura. Eficacia social del discurso literario, Programa IB / 2016 de la Universidad de Salamanca.
} 
$\mathrm{M}$ ichael Onfray en su obra Las sabidurías de la antigüedad. Contrahistoria de la filosofía I pone de relieve que «la historiografía dominante en el Occidente liberal es platónica» y añade, en este sentido, que «en nuestra vieja Europa los anales de la disciplina filosófica responden al punto de vista idealista». Su libro busca, en contrapartida, «mirar al otro lado del espejo platónico para descubrir paisajes alternativos» y proponer una historia de la filosofía «que no se constituya contra el cuerpo... sino con el cuerpo» (26). En definitiva se propone trazar una historia de la filosofía calificable de «hedonista» en la que ocuparía un lugar destacado el pensamiento de Epicuro, que en época helenística abrió las puertas de su escuela, el Jardín, a todo aquel que quisiera participar de su filosófica búsqueda de la felicidad.

Pues bien, es igualmente la intención de alguno de nuestros más destacados poetas de hoy reivindicar un lugar clave para el cuerpo, tan denostado, y una vida feliz a través de y con este, alejándose así en su poesía de los planteamientos idealistas que a lo largo de siglos han encorsetado la historia de nuestra cultura. Y qué mejor modo de hacerlo que rescatando la esencia del pensamiento que Epicuro legara a la posteridad y que en gran medida ha llegado hasta nosotros de la mano de algunos de los grandes poetas latinos (Lucrecio, Catulo, Horacio, Virgilio...).

En trabajos anteriores (Álvarez, 2010, 2013) he dedicado mi atención a estudiar cómo y en qué medida las ideas de este filósofo y su escuela han ejercido una influencia notable en la obra de la poeta andaluza Aurora Luque, nacida en la década de los 60 y vinculada a lo que críticos como SánchezMesa han denominado «una poética de clasicismo postmoderno» (41). Pues bien, es el propósito de este trabajo continuar rastreando en ella este vínculo, en especial en sus dos libros más recientes, ambos publicados en el 2015 (Cuaderno de Flandes y Personal y político) y en qué medida dicho pensamiento determina los trazos de una vida plena.

La huella del mundo clásico es prevalente en la obra poética de Luque y el pensamiento epicúreo no es sino parte importante, es verdad, pero tan sólo una muestra más de aquella. Luque es, como bien es sabido, profesora de lenguas clásicas y traductora de estas. Su evidente amor por el mundo grecolatino permea la totalidad de su obra, de una manera más personal si cabe que incluso la de poetas de generaciones precedentes como la de los 50 (entre los destacamos a Jaime Gil de Biedma y José Manuel Caballero Bonald a los que tanto admira) o la de los Novísimos como el latinista Jaime Siles, por ejemplo.

La principal línea de conexión entre la obra de Luque y el pensamiento epicúreo son los poetas latinos: Horacio y Virgilio, y, por supuesto, Ovidio y Catulo (Álvarez, 2013: 78-79). La referencia a Epicuro es, no obstante, abierta, desde el momento en que llega a titular uno de sus poemarios La siesta de Epicuro y a proclamar a través de la voz poética de su poema «Epicuro en la Quinta Avenida», refiriéndose a su lectura juvenil de la novela Fabiola del Cardenal Wiseman, «Tal vez el cardenal me hizo epicúrea» (11). Al mismo tiempo tiene bien presente nuestra poeta la recuperación que de esta 
filosofía de vida hace el filósofo Michael Onfray y lo deja patente cuando introduce este poemario con una significativa cita de Las sabidurías de la antigüedad:

¿El mar que hay que cruzar? La filosofía idealista en su triple fórmula platónica, cristiana y alemana ¿La corriente submarina? ¿Aquel famoso río Alceo? La filosofía hedonista: materialista, sensualista, existencial, utilitarista, pragmática, atea, corporal, encarnada... (27).

Y será el epicureísmo de Horacio, más hedonista si cabe que el del propio maestro Epicuro, a través de su famoso tópico carpe diem el que esté presente de lleno en toda su producción poética, hasta el punto de que su obra se articula en gran medida en torno a él. Los títulos de uno de sus poemarios (Carpe noctem) y de tres de sus antologías (Carpe mare, Carpe verbum y Carpe amorem) dejan de ello constancia. Pero, si bien en estos títulos o en algunos versos de sus poemarios el tópico irrumpe en su forma original o ligeramente transformado, es el tono imperativo que se ve en el poema introductorio de La siesta de Epicuro, «Fruta del día» («Tienes que vivir vidas...» (9)) el que se impone y repite en el poema inicial de Personal y político, «Carboneras, verano 2013»:

Empápate de luz azul los ojos.

Esta mañana de olas voluptuosas arde el mundo de pura plenitud (9).

El tópico horaciano está directamente vinculado en Luque a la corporeidad ${ }^{2}$ y esta, al igual que en la doctrina epicúrea, estrechamente unida a los sentidos. En sus Máximas capitales Epicuro se pronuncia así: «Por mi parte, no sé qué idea puedo hacerme del bien si suprimo los placeres del gusto, del amor, del oído y los suaves movimientos que de las formas exteriores recibe la vista. » $(28)^{3}$.

El percibir, el saber sentir, es lo que, como bien indica el filósofo alemán Wilhelm Schmid en su breve ensayo La felicidad, proporciona auténtico sentido a la existencia: «Quien desarrolla totalmente los sentidos se ve inundado por la vida y percibe las infinitas manifestaciones del mundo.» (42). En la poesía de Luque son constantes las menciones a ellos, como vemos ocurre con la vista en el fragmento de Personal y político previamente citado y se aprecia en significativas composiciones de poemarios anteriores ${ }^{4}$. Ante el carácter limitado de la vida, abrazar el placer que ellos nos proporcionan es clave, nos recuerda la famosa Máxima XX de Epicuro de la que la propia Luque se sirvió como epígrafe para introducir una de las secciones de La siesta de Epicuro ${ }^{5}$ :

Pero el pensamiento, que se ha dado cuenta del fin y límite de la carne, y que ha diluido los temores de la eternidad, nos prepara una vida perfecta, y para nada precisamos ya de un tiempo infinito. Porque ya no se rehúye el placer. Y cuando las circunstancias nos llevan al momento de dejar la vida, no nos vamos de ella con el sentimiento de que algo nos faltó para haberla llevado mejor.

\footnotetext{
${ }^{2}$ El cuerpo, junto a la piel, va de la mano del deseo desde sus primeros poemarios, en composiciones como «Cambio de piel» de Carpe noctem, «Sextina-brindis» de Camaradas de Ícaro o la significativa serie de haikus titulados «Letras para Carmen Linares» de la sección «El Jardín de Filodemo» en La siesta de Epicuro (Álvarez, 2013: 77-97). Sin deseo, sin el cuerpo, no hay plenitud vital posible, nos dice nuestra autora poema tras poema.

${ }^{3}$ Los textos atribuidos a Epicuro y su escuela proceden de la traducción de los fragmentos y testimonios escogidos de García Gual incluidos en Filosofía para la felicidad.

${ }^{4}$ Así lo vemos en «Canción» de Carpe noctem o «En Radio 3» de La siesta de Epicuro, por ejemplo.

${ }^{5}$ Me refiero a la última, «La tumba de Lucrecio».
} 
Luque se hace eco del alcance de este pensamiento epicúreo y lo sigue a rajatabla. Saberse mortal y asumirlo sin temor nos permite disfrutar de la vida en plenitud, incluso cuando se llega a la antesala de la vejez. Y es sobre esto sobre lo que reflexiona la voz poética de varias composiciones de Personal y político, como en el poema «La catástrofe», donde aquella dialoga con La Vejez, «una fontanera, una registradora de averías» que le empuja una vez más a aprovechar el instante:

Todo es fontanería mal cuidada.

No dejes gotear los sueños que te queden:

se agotan las reservas y no tendrás talleres disponibles.

Nunca dejes vacía la bodega:

ve cambiando el crianza del placer inmediato

por el viejo coñac, ese actor de doblaje.

Que no se vuelque el tanque del deseo. Y mima los depósitos

de la vida gastada (43).

Ante la vejez se puede optar por un hedonismo de corte ascético, aquel que proporciona ese «viejo coñac»y al que empuja la voz del propio personaje un poco más adelante en el mismo poema: «Pero busca, hay remansos / y secretos estanques / que brillan como cruda esmeralda todavía.» (43). $\mathrm{Y}$ entre estos «remansos» puede incluirse el disfrute a través de la memoria, tema recurrente en su poesía, que podemos igualmente vincular al maestro Epicuro, a quien se atribuye el siguiente pensamiento: «El recuerdo de los bienes pasados es muy importante para la vida feliz.» (García GualLledó, 2013: fr. 38).

La idea no es ajena a Personal y político donde la voz poética del ya citado «Carboneras, verano 2013» sugiere:

\footnotetext{
Esta mañana de olas voluptuosas arde el mundo de pura plenitud. Arenas primordiales, azul denso, sol claro. Guárdalo en la memoria, protegido, como licor que abrigue cuando llegue el glaciar de la vejez (9).
}

Schmid contempla el recuerdo como instrumento de consecución de la plenitud, esa «felicidad constante y moderada a la vez, que se extiende y perdura en el tiempo» (28-29) y explica que dicha «plenitud» se experimenta a veces «con la mirada desde la distancia, que ve la vida sometida a un contexto, con todas las luces y sombras que constituyen la riqueza de una vida plena entre el nacimiento y la muerte.» (29). Bien consciente de ello es sin duda nuestra poeta.

Otra opción, sin embargo, que fluctúa con esta y que no está con ella reñida, es la de un hedonismo más activo, como el de esta epicúrea profesora de latín en «De balneario en balneario», composición perteneciente igualmente a su último poemario:

Mi vieja profesora de latín, epicúrea en las décadas de Franco, se divorció, se jubiló y se puso a honrar el noble espíritu de Roma. «Vive de balneario en balneario, critica algún pariente rencoroso. 
Espléndida liturgia de una vida consagrada a la lengua de Catulo: bañar morosamente el propio ocaso por las termas ibéricas más pijas (25).

Y este hedonismo activo no es otro que el que asentara en la Campania el sirio Filodemo de Gádara, en la famosa villa de Pisón en Herculano (Onfray, 2007: 230-233) y que rezuma en los versos de Horacio o del citado Catulo. En efecto, Filodemo «flexibiliza la austeridad y el ascetismo del comienzo al llevar la sabiduría del Jardín hacia un hedonismo menos riguroso», nos dice Onfray, y «para hacerlo modifica la doctrina en dos campos: la estética y la política. Propone, por un lado, una teoría ampliada de las bellas artes y, por otro lado, una invitación ciudadana no tan radicalmente rupturista respecto de la ciudad.» (235-236). Recordemos la postura radical que se atribuye en estos dos aspectos al fundador del Jardín. Epicuro desprecia la cultura y todo lo que con esta se relaciona (Fr.9: «iHuye, afortunado, a velas desplegadas de toda forma de cultura!»), así como la política (GV 58: «Hemos de liberarnos de la cárcel de los intereses que nos rodean y de la política.»). En ambos aspectos cabe tachar a Luque de «epicúrea poco convencional», haciendo un guiño al conocido poema de González Iglesias ${ }^{6}$, otro de los grandes epicúreos de nuestra poesía. Comencemos por la cultura.

No es ajeno a su obra el elogio de la lectura, como se aprecia indirectamente en esos homenajes a alguno de sus poetas de cabecera en Camaradas de Ícaro y de una manera más abierta en el poema «Simbad o Don Quijote» de Personal y político:

Todos somos Simbad o Don Quijote.

[...] Ir desde la aventura a su relato

o viajar de los libros a la vida.

Simbad vivió dos vidas, al vivir y al narrarse.

El caballero extrajo de los libros

un programa de noble bonhomía (21).

Y añade más adelante en el poema «Así los libros dotan de equipaje a quien vive», reconociendo el papel fundamental de la lectura para proporcionar sentido a la existencia. Insiste en ello en «Los postres de Jujú», un cálido homenaje a Ana María Matute y a los libros que hicieron felices los días de la infancia, haciéndonos conscientes de que esa felicidad quedaría en la vida adulta en ocasiones a ellos limitada: «Cuando ya comenzábamos a saber que tendríamos / que relegar en libros a la felicidad / en tanto que plausible o inmediata...» (59).

La literatura para Luque está intrínsecamente vinculada a la vida y evocar sus lugares es otra manera de vivirla intensamente. Nos lo recuerda ya en su poemario Transitoria a través del poema «Literatura aplicada» («Siempre me consoló viajar a cualquier parte/ con un vago pretexto literario» 44), pero más que nunca si cabe en su «Cuaderno vieja América» de Personal y político, donde recorre esos lugares en varios de sus poemas. Así en «Yo quería ser Jo o los tres elixires de Miss Alcott» (83), la voz poética, sumamente identificable con la de la autora, informa «Jo quería ser Jo. Escribir y ser libre./ Yo quería ser Jo. He puesto empeño en ello». A través de la similitud fonética entre el nombre

\footnotetext{
${ }^{6}$ Me refiero al poema «Unconventional Epicureans» de Un ángulo me basta.
} 
anglosajón «Jo» y el pronombre sujeto de primera persona singular en español «yo» se insiste en la búsqueda de consolidación de la propia identidad de la voz poética emulando la del personaje de May Alcott $^{7}$. Dirigiéndose a esta, exclama al final del poema:

\author{
Pero escribiste a Jo en la calle McDougall, \\ en Manhattan. He viajado a esa puerta \\ como el que peregrina \\ porque un santo le ayuda a usar las piernas. \\ Y las gracias te doy \\ por darme tu Semilla de Inquietud \\ con un brindis secreto \\ de elixir que no nombro (83-84).
}

La literaria casa donde la protagonista de Little Women se convirtiera en escritora se torna a su vez para la voz poética en un cuasi-santuario al que acudir en agradecimiento por esos libros, ese libro, que, ya en versión abreviada, ya íntegra, cambió primero la vida de una niña («yo tenía seis años»), de una adolescente después («yo tenía dieciséis») y contribuyó a la forja de una escritora, y por ende de una mujer libre, a miles de kilómetros de distancia.

Ese mismo peregrinaje lo encontramos en el poema «La linterna», en este caso a la casa de la poeta Emily Dickinson en Amherst: «¿Qué vienen a rogar los peregrinos / a la casa de Dickinson?» (99) se pregunta la voz poética e incluyéndose concluye en esta reflexión metapoética:
Apuntamos linternas encendidas
hacia el magma o el pozo subterráneo.
El círculo de luz busca una veta
de palabras hundidas que fulguren como se buscan minas de topacios en países abruptos y feroces.
Como se buscan aguas curativas en épocas de plagas y sequías (99).

La literatura, en definitiva, ensancha la experiencia vital de nuestra autora, le da alas para vivirla en libertad y sirve de combustible a su propia creación poética.

En lo que se refiere a la política, a su compromiso como ciudadana, ya en La siesta de Epicuro encontramos algunos poemas abiertamente críticos con la actualidad española, como los dos últimos de la serie «Catulo y yo», ambos con títulos bastante ilustrativos, «Ocio» y «Senatus Hispanus» que juegan intertextualmente, como todos los de la serie, con poemas del veronés (Álvarez, 2013: 85-86) ${ }^{8}$.

\footnotetext{
${ }^{7}$ La novela Little Women (Mujercitas) aborda la historia de cuatro niñas que llegan a convertirse en mujeres durante la época de la guerra civil estadounidense (1861-1865) en la ciudad de Concord, Massachussetts. La segunda de ellas, Josephine (Jo), es la que muestra una personalidad más independiente y rebelde y sueña con convertirse en escritora, lo que conseguirá finalmente en la ciudad de Nueva York y tras su encuentro con el profesor Bhaer, de origen alemán, con el que acabará contrayendo matrimonio.

${ }^{8}$ Sobre la implicación socio-política de la poesía de Luque remitimos al trabajo de Dolores Juan Moreno «¿Qué acabó con Babelias y Marbellas? Reflexión social y palabra comprometida en la poesía de Aurora Luque», donde la autora analiza los diversos ámbitos de compromiso de nuestra poeta a la que califica de poeta-reciclaje: el producto de su poesía es el resultado de la reutilización de unos materiales provenientes de todos los pasados a la vez que, depurados por el cedazo del compromiso estético, se conjugan con las necesidades del presente ofreciendo al fin un material aprovechable para el consumidor-lector actual (263).
} 
Sirven estos de preámbulo a una tendencia que cuajará en Personal y político, poemario en cuyo título se hace eco la autora de un popular lema feminista surgido del ensayo The Personal is Political que en el año 1969 escribiera la feminista norteamericana Carol Hanish. Dolores Juan Moreno destacó en su momento la reflexión comprometida de Luque en cuanto al «papel y lugar de la mujer en la historia» (2013: 268), y esta resulta más obvia si cabe ahora, como comprobamos al leer un poema como «Disidanzas (Homenaje a Nancy Spero)», dedicado a la artista y activista norteamericana que enfocó su producción en temas vinculados a las mujeres y sus representaciones en diversas culturas, sin omitir el mundo clásico. Así nos lo recuerda la voz poética de este largo poema en el que una bailarina, representada con claros ecos helenos por la artista en las paredes de la estación de metro de la calle 66-Lincoln Center de Nueva York, es identificada por Luque con una ménade de nombre Nancy que salta del mosaico en el que ha sido incrustada para recorrer medio Manhattan y acabar arrojándose a las «azulidades oceánicas / verdes limpias homéricas» (78) y morir en ellas. En su periplo neoyorquino la voz poética da cuenta de un crisol de mujeres que aportan sus personales riquezas a la artista, hispanas y afroamericanas fundamentalmente, aunque también hay un metafórico hueco para la María Zambrano de la época de su exilio mexicano en Morelia:

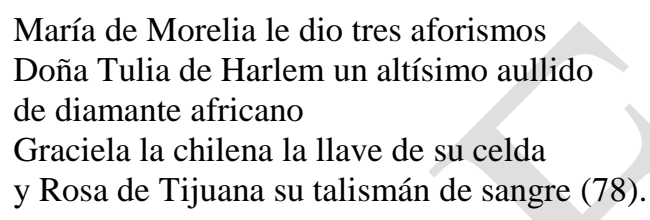

Luque hace referencia de este modo a tantas mujeres diversas que fueron de un modo u otro reivindicadas en las obras de Spero, como, por ejemplo, las mujeres torturadas durante la dictadura chilena, y a las que esta dio la voz que otros les negaron las más de las veces con una cruenta violencia ${ }^{9}$.

«La ciudad se mezcla en la escritura y la memoria lírica va unida a la experiencia de la ciudad», recuerda la contraportada de Personal y político y esa experiencia es reflejada con crudeza, como vemos en el poema «Los irrelevantes», en el que el ojo de la autora no es ajeno a la dura realidad de la inmigración: «El joven alto, enjuto./ cruzó el mar como escapan/ los ciervos de un incendio. » (75). Ni lo es asimismo en «Quirópteros» a una realidad más amplia, la de un mundo, el de hoy, que permite que gran parte de su población muera de hambre y de enfermedades, como el Ébola, que no resulta rentable erradicar: «Un niño hambriento chupa unos cartílagos / y la sangre le brota por los ojos.». Rotunda concluye con una indirecta alusión a las películas de vampiros: «Y no salva el amor como en el cine» (15).

\footnotetext{
${ }^{9}$ Sobre la presencia de las mujeres en la obra de Spero véase el trabajo de Lisa Tickner «Images of women and La peinture féminine en Nancy Spero». Institute of Contemporary Arts, London (1987), pp.5-19. La obra de la artista a partir de 1972 se compromete completamente con el movimiento feminista con el propósito de narrar la historia de las mujeres, poniendo un énfasis especial al hacerlo en su victimización. Véase en este sentido MAYAYO, P. (2003): «¿Vencedoras o vencidas? Las mujeres y la guerra en la obra de Nancy Spero», en M. Nash y S.Tavera, Las mujeres y las guerras. El papel de las mujeres en las guerras de la edad antigua a la contemporánea, Barcelona, Icaria, pp.187-196.
} 
La inclinación a la reflexión sociopolítica tampoco falta en Cuaderno de Flandes, donde encontramos un poema, no carente de acidez, sobre el estado actual de la educación en nuestro país que lleva por título «La muerte de Erasmo»:

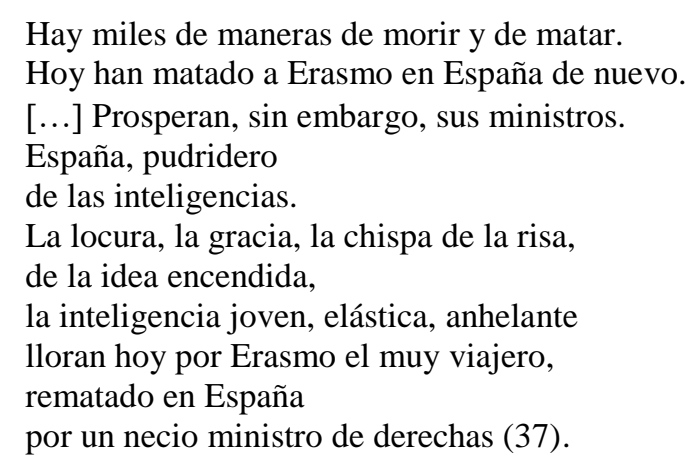

Si como defiende Wilhelm Schmid encontrar sentido a la existencia tiene aún más valor en la vida que la propia felicidad, esta vertiente cada vez más consolidada en la última poesía de Luque contribuye a ello pues, como argumenta el pensador alemán, en el ámbito privado y en el social crea sentido positivo la participación: sentirse miembro de una comunidad, ciudadano de una sociedad y con ello experimentar el «sentido civil» literalmente (47). Y Luque se siente ciertamente ciudadana, ciudadana y mujer, lo que deja muy claro en varios de los poemas comentados.

El hecho de que el epicureísmo luqueano se incline más hacia «el epicureísmo hedonista romano» (Onfray, 2007: 231) en su doble implicación estético-política no impide que nuestra poeta se acoja a la tradicional valoración y elogio de la existencia lenta, amena, del fundador de la escuela en su afán de obtener la serenidad que nos lleva a la vida feliz. Dicha existencia igualmente se vincula a la naturaleza desde la poesía de Horacio y Virgilio el famoso locus amoenus identificado con una campestre estampa en la que no faltan un río o un arroyo ( «las curvas del riachuelo/ veloz que cruza la campiña dulce» lo caracteriza Horacio en su Arte poética en traducción aquí de González Iglesias) y que Luque, por su parte, transpone al $\operatorname{mar}^{10}$. El mar, omnipresente desde sus primeros poemarios y que es por excelencia el mar de Grecia, es el que evoca en su programático poema «Gel» de Carpe noctem donde la voz poética, deleitándose en el pequeño gesto de su baño cotidiano, exclama al rozar su cuerpo con una esponja adquirida en la isla de Hydra:

\author{
Me punza una emoción tan anacrónica, \\ un penoso latir, hondo y absurdo, \\ por ese mar. Por ese sólo mar. Busco una dosis \\ de mares sucedáneos. \\ Como podría desintoxicarme. \\ Dependo de por vida \\ de una droga. De Grecia (15).
}

\footnotetext{
${ }^{10}$ Curiosamente el mar también tuvo un peso importante en los epicúreos que se reunían en la Villa de Pisón en Herculano en torno a la figura de Filodemo. Así lo evoca Onfray: «Hasta donde alcanza la vista, los interlocutores asisten al espectáculo de la vastedad de Mediterráneo: reflejos solares malvas, azules, verdes y negros del agua mágica y magnífica, aceites que lustra el sol poniente o crestas ondulantes y espumosas cuando el viento sopla con fuerza...» (226).
} 
Es también el que vuelve en esas «arenas primordiales, azul denso, sol claro» (9) del poema que abre Personal y político, o en «La palabra gaviera» de este mismo poemario, donde la poeta lleva a cabo un muy particular homenaje a la portuguesa Sofía de Melo quien, como esta nos dice «Pone a Grecia su proa, porque se sabe cíclada» (31). y, a través de ella, a la prematuramente fallecida Ana Santos Payán, a la que está dedicado el poema ${ }^{11}$. Pero es, igualmente, el mar de un bello poema en prosa perteneciente a su Cuaderno de Flandes titulado «Oración a Nahalania», de título alusivo a una divinidad marina mencionada en los Archivos del Norte de Marguerite Youcenar, de la que Luque significativamente observa:

Habitabas las primeras mañanas del mundo y ahora, en los ocasos, tu nombre continúa evocando una tibia placidez: la misma que nos traen las olas grises, enrolladas en suaves y larguísimos tirabuzones horizontales, sobre una arena de crujientes y límpidas conchas astilladas (25).

Hasta aquí nuestro recorrido en sus últimos poemarios por algunos aspectos de la inclinación epicúreo-hedonista de esta conocida poeta, una de las más clásicas de nuestra posmodernidad, en su particular búsqueda de una vida plena, búsqueda en la que no sólo Epicuro sino su tardío discípulo Filodemo de Gádara y varios poetas latinos como Horacio y Catulo que directa o indirectamente recibieron las enseñanzas del fundador del Jardín, mantienen plena vigencia. Observamos, por un lado, el reclamo del cuerpo y los sentidos, siempre con el Carpe diem como lema de un hedonismo activo del que no se prescinde con la llegada a la vejez y que en absoluto está reñido con el disfrute de la cultura y con la toma de partido ante la vida socio-política, con su reivindicación de un lugar para la mujer a la cabeza. Por otro Luque se inclina a veces hacia un hedonismo de corte más ascético que busca refugio en la memoria y que encuentra su materialización en muchas ocasiones en un muy personal y marino locus amoenus. Sirvámonos de estos sus nuevos versos para aprender a vivir con mayor intensidad en nuestra personal búsqueda de una vida en plenitud.

\section{Bibliografía}

ÁlvAREZ, J. (2010): «La siesta de Epicuro: valoración del instante y hedonismo vital a través del haiku», en J. M. TORRES POU, ed., Orientalismos. Oriente y Occidente en la literatura y las artes de Hispanoamérica. Barcelona, PPU.

(2013): Tradición clásica en la poesía de Aurora Luque. Figuras, formas e ideas. Sevilla, Renacimiento.

Horacio Flaco, Q. (2012): Arte poética. Ed. y trad. de Juan Antonio González Iglesias, Madrid, Cátedra.

GARCía GuAl, C. - Lledó, E. - HAdOT, P. (2013): Filosofía para la felicidad. Epicuro. Madrid, Errata naturae.

\footnotetext{
${ }^{11}$ Ana Santos Payán era co-propietaria junto a su marido de la editorial almeriense El gaviero. Antes de morir extendió una propuesta a la RAE para conseguir que fuera incluido en el diccionario el femenino de la palabra «gaviero». Aurora Luque escribió este poema para acompañar dicha solicitud.
} 
180 | Tropelías. Revista de Teoría de la Literatura y Literatura Comparada, 30 (2018) Josefa Álvarez Valadés

GónZALEZ IGLESIAS, J. A. (2002): Un ángulo me basta. Madrid, Visor.

JuAn Moreno, D. (2013): «¿Qué acabó con Babelias y Marbellas? Reflexión social y palabra comprometida en la poesía de Aurora Luque», en M. ${ }^{a}$ Teresa NAVARRETE NAVARRETE, Miguel Soler Gallo, eds., Ay, iqué triste es toda la humanidad! Literatura, cultura y sociedad española contemporánea. Roma, Aracne, pp. 261-270.

LuQUe, A. (1989): Problemas de doblaje. Madrid, Rialp.

- (1994): Carpe Noctem. Madrid, Visor. (1996): Carpe mare. Málaga, Miguel Gómez Ediciones.

(1998): Transitoria. Sevilla, Renacimiento.

- (2003): Camaradas de Ícaro. Madrid, Visor.

- (2004): Carpe Verbum. Antología temática. Selección y prólogo de Francisco Fortuny. Málaga, Área de Cultura del Ayuntamiento de Málaga, 2004.

- (2007): Carpe amorem. Ed. de Ricardo Virtanen, Sevilla, Renacimiento.

- (2008): La siesta de Epicuro. Madrid, Visor.

- (2015): Cuaderno de Flandes y otros poemas. Ed. bilingüe en francés y trad. Regina López Muñoz, Sevilla, Ediciones en huída.

- (2015): Personal y político. Sevilla, Vandalia.

ONFRAY, M. (2007): Las sabidurías de la antigüedad. Contrahistoria de la filosofía, I. Trad. Marco Aurelio Galmarini. Barcelona, Anagrama.

SÁnCHEZ-Mesa MARTínEZ, D. (2007): Cambio de siglo. Antología de la poesía española 1990-2007. Madrid, Hiperión.

SCHMID, W. (2010): La felicidad. Todo lo que debe saber al respecto y por qué no es lo más importante en la vida. Trad. Carmen Plaza y Ana R. Calero. Valencia, Pre-Textos. 